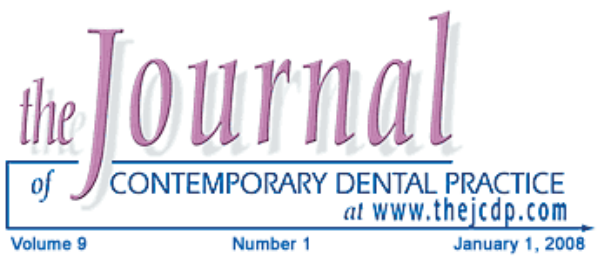

\title{
Canalicular Adenoma Presenting as an Asymptomatic Swelling of the Upper Lip: A Case Report
}

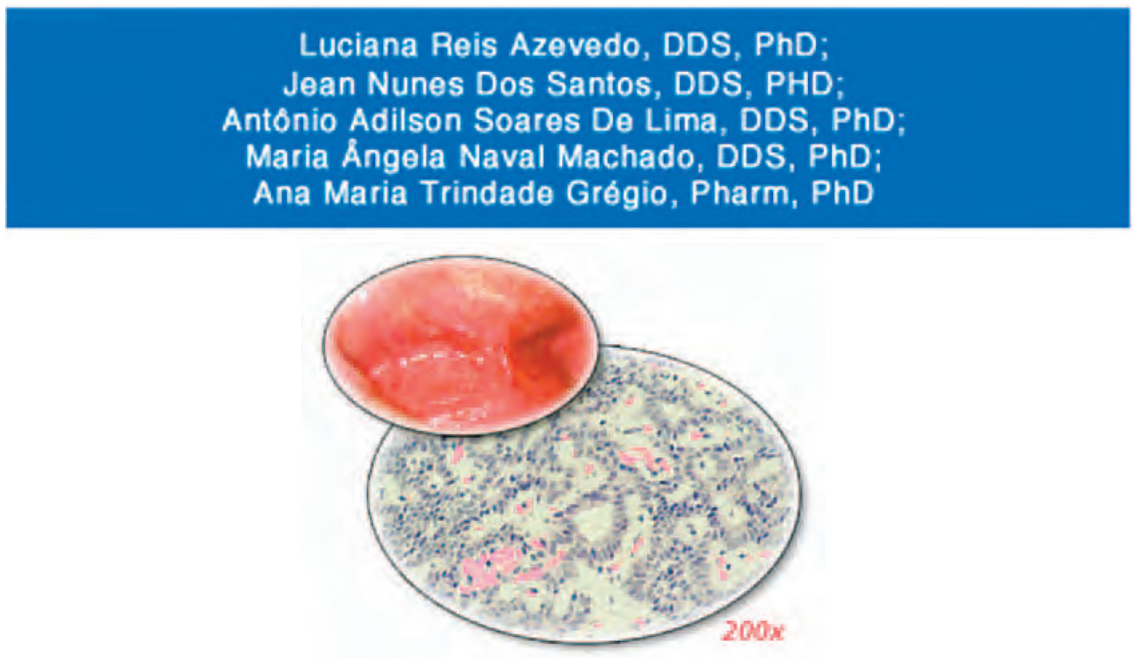

\section{Abstract}

Aim: The purpose of this report is to present the clinical and histological features of a canalicular adenoma (CA) occurring in the upper lip and vestibular fornix of a 62-year-old woman.

Background: $\mathrm{CA}$ is an uncommon benign salivary gland tumor occurring almost exclusively in the intraoral glands. This tumor has often been referred to as a variant of the basal cell adenoma. However, the World Health Organization's latest histological classification of salivary gland tumors recognizes it as a separate entity under the broader heading of monomorphic adenoma, which is not related to any of the subtypes of basal cell adenomas.

Case Report: A 62-year-old woman with a chief complaint of an extraoral swelling in the upper lip. The evolution of the lesion was not known by the patient who recognized it when she touched her upper lip and found "an acne" on it. The patient wore complete dentures since age 17 and was not aware of any pain or tenderness in the area. Extra and intraoral examination revealed a mobile nodular lesion located in the right aspect of the upper lip near the nose and in the vestibular fornix between the lateral incisor and canine. Microscopic examination confirmed the final diagnosis of CA. The patient is currently free of disease 54 months after surgical excision of the tumor.

Summary: Local excision of symptomatic nodules seems to be sufficient to manage patients with multifocal $\mathrm{CA}^{10}$ But, unlike other benign tumors, CA may need a longer follow-up due to its tendency towards multifocal occurrence and late recurrence. ${ }^{3,7}$

(c) Seer Publishing 
Keywords: Canalicular adenoma, CA, salivary gland tumors, monomorphic adenoma

Citation: Azevedo LR, Dos Santos JN, De Lima AAS, Machado MÂN, Grégio AMT. Canalicular Adenoma Presenting as an Asymptomatic Swelling of the Upper Lip: A Case Report. J Contemp Dent Pract 2008 January; (9)1:091-097.

\section{Background}

Canalicular adenoma (CA) is an uncommon benign salivary gland tumor occurring almost exclusively in intraoral glands and accounts for $1 \%$ of all salivary gland neoplasms. ${ }^{1-5}$ In a series of 213 cases of intraoral minor salivary gland neoplasms, $\mathrm{Yin}^{6}$ found 25 cases of CA which was the second most common benign gland tumor found.

Historically, this tumor has often been referred to as a variant of the basal cell adenoma. However, the World Health Organization's latest histological classification of salivary gland tumors recognizes it as a separate entity under the broader heading of monomorphic adenoma which is not related to any of the subtypes of basal cell adenomas. ${ }^{3,7-9}$

CA usually arises in the minor salivary glands with the upper lip being the most common site accounting for $70-90 \%$ of all tumors followed by the buccal mucosa and palate..$^{1-13}$ Involvement of parotid glands is extremely rare. ${ }^{7,8,14}$ This tumor occurs mainly in elderly people after 60 years of age $^{1}$ and shows a slight female predilection. ${ }^{2-6,8,11-13}$

$\mathrm{CA}$ is an older term than either basal cell adenoma or monomorphic adenoma, and the origin of the term is unclear. ${ }^{15}$ According to Triantafyllou et al. ${ }^{16}$ salivary parenchyma cells proliferate and activate dormant matrix genes. Proliferating cells fail to develop anatomical coupling with nerves and synthesize glycosaminoglycan, a primitive, or immature glycoprotein. Eventually a tumor with embryonal features is formed.

CA clinically is usually the color of the overlying mucosa and manifests as a painless, slowly growing encapsulated submucosal mass which may be firm or slightly fluctuant on palpation. ${ }^{1-4,7,13,15}$ It is typically smaller than $2 \mathrm{~cm}^{2,4}$ The overlying mucosa is rarely ulcerated. ${ }^{4,11,14}$

CA is not likely to be diagnosed preoperatively using fine needle aspiration or on clinical inspection. ${ }^{7}$ Clinically, it can be confused with mucoceles, epidermal inclusion cyst, nasolabial cyst, lipoma, benign peripheral nerve lesion, benign fibrous lesions, mucous retention cyst, and pleomorphic adenoma. ${ }^{1,3,4}$ Adenoid cystic carcinoma and basal cell adenoma must be included in the differential diagnosis. ${ }^{2,13}$

\section{Case Report}

\section{Diagnosis}

In August, 2001 a 62-year-old woman was referred to the Dental Clinic at Pontifícia Universidade Católica do Paraná in Curitiba, PR, Brazil with a chief complaint of an extraoral swelling in her upper lip. She did not know the exact evolution of the lesion and was only aware of it when she touched her upper lip and found "an acne" on it. The patient had been wearing complete dentures since she was 17 years old and was not aware of any pain or tenderness in the area. Extraoral and intraoral examination revealed a firm, mobile nodular lesion measuring 0.3 to $0.4 \mathrm{~cm}$ located near the nose in the right portion of the upper lip and extending to the vestibular fornix between lateral incisor and canine (Figure 1).

The overlying mucosa appeared slightly reddened. There was no cervical lymphadenopathy and no alteration of the nasolabial sulcus. The initial diagnostic hypothesis was mucocele, followed by CA and nasolabial

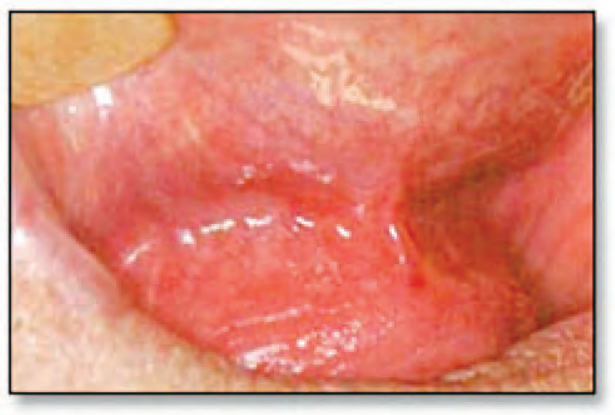

Figure 1. Discrete intraoral swelling in the upper lip of a 62-year-old edentulous woman. 


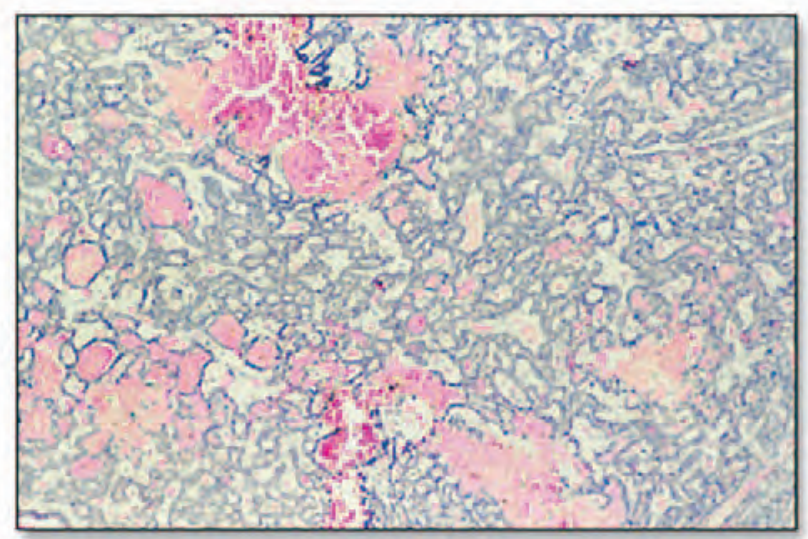

Figure 2. Typical histology of a CA composed of single layers of cubo-columnar cells in cords, forming "canal-like" structures (Hematoxylin-eosin stain; original magnification $X 100)$.

cyst. A mucocele was the first consideration due to its clinical characteristics and high frequency in the lips. CA was added to the list of possibilities since the most common site for this tumor is also in the upper lip. The nasolabial cyst was also considered because of the anatomic location and the age of the patient despite the apparent normality of nasolabial sulcus because it could have been an incipient lesion.

An excisional intraoral biopsy was performed under local anesthesia. Microscopic examination revealed a tumor encapsulated and well circumscribed. The epithelium was welldemarcated. The tumor was composed of single and double layers of cubo-columnar cells in cords, forming "canal-like" structures (Figures 2 and 3 ).

Uniform epithelial cells were arranged in an anastomosing monolayered duct-like pattern. The stroma consisted of loose fibrovascular tissue with dilated blood vessels (Figure 4). There was no evidence of satellite islands. The final diagnosis was CA.

\section{Treatment}

As a result of the surgical elimination of the tumor during the excisional biopsy, the patient is currently free of disease 54 months after surgery (Figure 5).

\section{Discussion}

It refers to a 62-year-old woman, showing an asymptomatic nodule in the upper lip that was initially noted extraorally. Mucocele was the first diagnostic hypothesis, followed by CA and

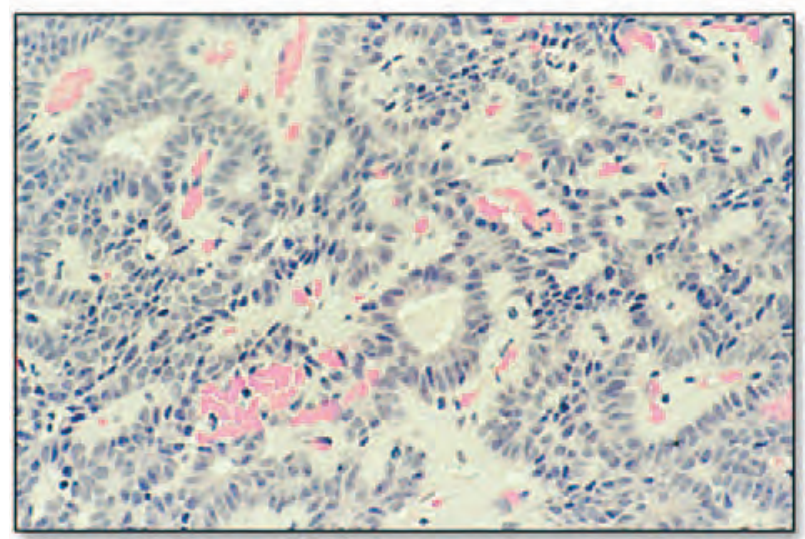

Figure 3. Photomicrography showing single and double layers of cubo-columnar cells in a fibrous stroma (Hematoxylin-eosin stain; original magnification X 200).

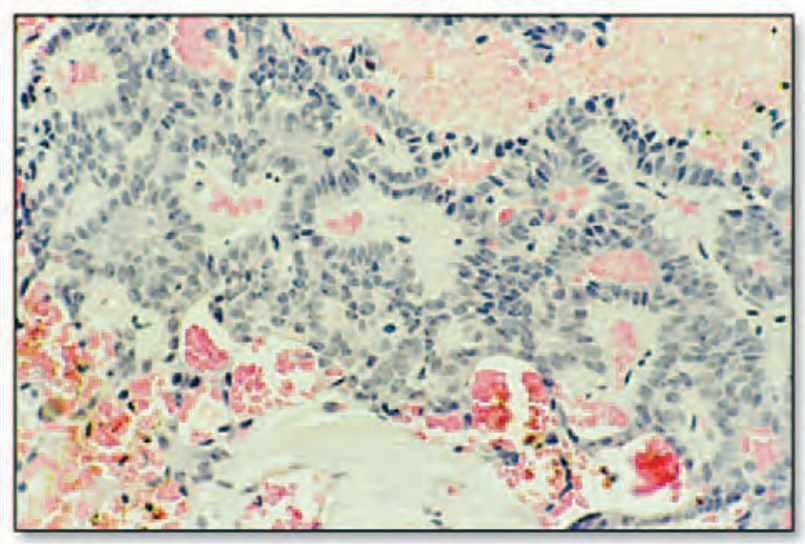

Figure 4. Glandular epitelial elements arranged in anastomosing monolayered duct-like pattern (Hematoxylin-eosin stain; original magnification X 200).

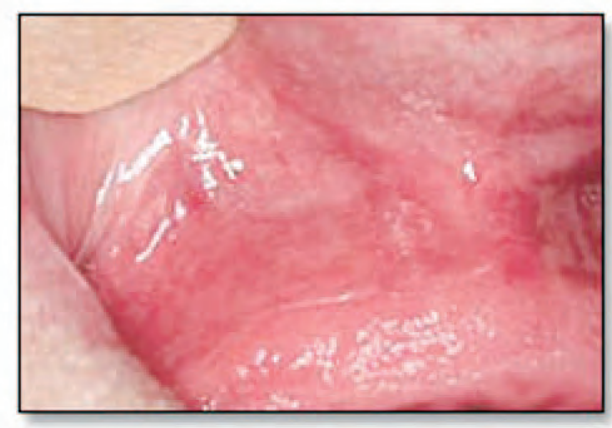

Figure 5. Upper lip and vestibular fornix showing characteristics of normality 54 months after surgery.

nasolabial cyst. This clinical case is partially in accordance with the findings of other studies presented previously.

Sometimes large and locally aggressive palatal CA may invade into the nasal cavity and cause 
partial obliteration of maxillary sinus and even destruction of the maxillary walls and hard palate, which can be verified by panoramic radiographs and a maxillofacial CT scan. ${ }^{14}$

The diagnostic value of a preoperative CT and MRI imaging for CA is emphasized by Yamada et al. ${ }^{12}$ The authors suggest CA should be included in the differential diagnosis when a nodule is located in the upper lip or buccal mucosa, the tumor is less than $2 \mathrm{~cm}$ in diameter, if the CT findings reveal a highly contrast-enhanced mass with a clear margin, and if the patient is over 50 years. MRI findings were not diagnostically specific.

Microscopically CAs are well circumscribed and generally composed of monomorphic epithelial cells that are frequently columnar in appearance and arranged in bilayered strands and ducts which may be associated with a focal collection of basaloid cells. The stroma is loose containing numerous thin-walled blood vessels with little collagen and few fibroblasts present. ${ }^{1-3,6,8,9,13-16}$ Scanning electron microscopic analysis revealed single-layered low columnar to cuboidal tumor cells lining the tubules that were uniform in size, shape, and structural appearance. Oval nuclei contain abundant euchromatin, sparse heterochromatin, and small nucleoli. . $^{5,7,8,17,18}$ The stroma of CA is primarily composed of mucoid material that is PAS-positive diastase resistant, mucicarmine-positive, alcian-blue-positive, and appears as a stellate reticulum. ${ }^{5,16,17}$ Cytologic features of CA are similar to those of tall columnar cells and small basal cells of the excretory ducts of salivary glands which supports a possible origin from excretory duct cells. ${ }^{5} \mathrm{CA}$ shows positive staining with anti-keratin, anti-vimentin, and anti-S-100 protein, but immunohistochemical analysis is seldom needed in view of the characteristic histologic and clinical appearance., ${ }^{2,19}$

A histological differential diagnosis between CA and basal cell adenoma (BCA) of the trabecular type seems necessary. BCA is composed of nests and multilayered cords of polygonal or cuboidal cells which sometimes exhibits peripheral palisading. The stroma of the latter is typically fibrous with less conspicuous blood vessels. ${ }^{8}$ These features serve as distinguishing features between BCA and CA.
A study comparing the extent of p63

immunoreactivity in adenoid cystic carcinoma, polymorphous low-grade adenocarcinoma, basal cell adenoma, and CA found CA did not exhibit any p63 immunoreactivity. ${ }^{20}$

Sometimes CA has a tendency to present as a multifocal lesion (approximately $22 \%$ of the cases) ${ }^{1}$ especially in the lips. ${ }^{2,3,4,6}$ It is this multifocal nature that can lead to recurrence which may happen over ten years later. ${ }^{7}$ The multifocality of these tumors may be identified only microscopically rather than clinically. ${ }^{2}$ It is highly likely the presence of tiny foci of tumor (microadenomas), developing in minor salivary glands at a site remote from the original lesion, ${ }^{1,4,10,16}$ are the cause of the multifocal nature of CA. ${ }^{9}$ However, it is important to emphasize these tumors are completely benign in behavior and no malignant transformation has been reported. ${ }^{3}$ Care must be taken to avoid interpreting the multifocal nature of these neoplasms as a "field of cancerization," leading to a diagnosis of malignancy and unnecessary surgery. ${ }^{1}$ In the present case there was no evidence of satellite islands in the microscopic examination. This negative finding excludes or avoids the misdiagnosis of malignancy.

Conversely, Khullar and Best ${ }^{10}$ suggest the multifocal occurrence and late recurrence of $\mathrm{CA}$ represents a field of neoplastic change although it appears to be benign. This indicates a high neoplastic potential because the recurrence may arise after a short time.

Adequate treatment consists of conservative surgical excision with a narrow margin of apparently normal tissue for minor salivary glands. ${ }^{1,2,3,12,14,16}$ Superficial or total parotidectomy, depending on extent and location of the tumor, is recommended for parotid lesions which yields excellent outcomes. ${ }^{2,14}$

\footnotetext{
Summary

Local excision of symptomatic nodules seems to be sufficient to manage patients with multifocal $\mathrm{CA} .{ }^{10}$ But, unlike other benign tumors, CA may need a longer follow-up due to its tendency towards multifocal occurrence and late recurrence. ${ }^{3,7}$
} 


\section{References}

1. Daley TD. The canalicular adenoma: considerations on differential diagnosis and treatment. J Oral Maxillofac Surg 1984;42:728-30.

2. Penner CR, Thompson LDR. Canalicular adenoma. Ear Nose Throat J 2005;84:132.

3. Queiroz LMG, Silveira EJD, Arruda MLS, Ramos CCF. A rare salivary gland neoplasm: multiple canalicular adenoma. A case report. Auris Nasus Larynx 2004;31:189-193.

4. Rousseau A, Mock D, Dover DG, Jordan RCK. Multiple canalicular adenomas. A case report and review of the literature. Oral Surg Oral Med Oral Pathol Oral Radiol Endod 1999;87:346-50.

5. Chen S-Y, Miller AS. Canalicular adenoma of the upper lip. An electron microscopy study. Cancer 1980;46:552-6.

6. Yih $\mathrm{W}-\mathrm{Y}$, Kratochvil FJ, Stewart JCB. Intraoral minor salivary gland neoplasms: Review of 213 cases. J Oral Maxillofac Surg 2005;63:805-810.

7. Philpott CM, Kendall C, Murty GE. Canalicular adenoma of the parotid gland. J Laryngol Otol 2005;119:59-60.

8. Daley TD, Gardner DG, Smout MS. Canalicular adenoma: not a basal cell adenoma. Oral Surg $1984 ; 57: 181-8$.

9. Nelson ZL, Newman L, Loukota RA, Williams DM. Bilateral multifocal canalicular adenomas of buccal minor salivary glands: a case report. Br J Oral Maxillofac Surg 1995;33:299-301.

10. Khullar SM, Best PV. Adenomatosis of minor salivary glands. Report of a case. Oral Surg Oral Med Oral Pathol 1992;74:783-7.

11. Parvizi F, Rippin JW, Edmondson HD. Canalicular adenoma of the palatal mucosa. Br Dental J 1996;181:27-8.

12. Yamada $\mathrm{H}$, Ishii $\mathrm{H}$, Seto $\mathrm{K}$, Kuwashima Y. Canalicular adenoma of the buccal mucosa: a case report with computed tomography and magnetic resonance imaging. J Oral Maxillofac Surg 2003;61:837-840.

13. Matsuzaka K, Murakami S, Shimono M, Inoue T. Canalicular adenoma arising in the upper lip: review of the pathological findings. Bull Tokyo Dent Coll 2004;45:229-233.

14. Smullin SE, Fielding AF, Susarla SM, Pringle G, Eichstaedt R. Canalicular adenoma of the palate: case report and literature review. Oral Surg Oral Med Oral Pathol Oral Radiol Endod 2004;98:32-6.

15. Gardner DG, Daley TD. The use of the terms monomorpfic adenoma, basal cell adenoma, and Canalicular adenoma as applied to salivary gland tumors. Oral Surg 1983;56:608-15.

16. Triantafyllou A, Coulter P, Scott J. Phenotypes in Canalicular adenoma of human mminor salivary glands reflect the interplay of altered secretory product, absent neuro-effector relationships and diversity of the microenviroment. Histopathology 1999;35:502-16.

17. Mintz GA, Abrams AM, Melrose RJ. Monomorphic adenomas of the major and minor salivary glands. Oral Surg 1982;53:375-86.

18. Guccion JG, Redman RS. Canalicular adenoma of the buccal mucosa. An ultrastructural and histochemical study. Oral Surg Oral Med Oral Pathol 1986;61:173-8.

19. Ferreiro JA. Immunohistochemical analysis of salivary gland canalicular adenoma. Oral Surg Oral Med Oral Pathol 1994; 78:761-5.

20. Edwards PC, Bhuiya T, Kelsch RD. Assessment of p63 expression in the salivary gland neoplasms adenoid cystic carcinoma, polymorphous low-grade adenocarcinoma and basal cell adenomas. Oral Surg Oral Med Oral Pathol Oral Radiol Endod 2004;97:613-9. 
About the Authors

Luclana Rols Azovedo, DDS, PhD

Dr. Azevedo is an Associate Professor in the Department of Oral Medicine at the School of Dentistry at Pontificla Unlversidade Catblica do Paraná In Curitiba, Paraná, Brazll. Her major research Interests Include the sallvary glands, oral pathology, and oral medicine. She is a member of LADR and SBPqO.

e-mall: Irazevedo@yahoo.com

Jean Nunes Dos Santos, DDS, PHD

Dr. Dos Santos serves as an Oral Pathologist in the Oral Surgical Pathology Laboratory at the Federal University of Bahla in Salvador, Bahla, Brazll. His research interests Include the sallvary glands, oral pathology, and oral medicine.

e-mall: pggo@pucpr.br

Antonlo Adilzon Soares Do Lima, DDS, PhD

Dr. De Lima is an Associate Professor and Chaiman in the Department of Oral Pathology at the School of Dentistry at Pontificla Universidade Catollica do Paraná in Curitiba, Paraná, Brazll. His research interests Include the salivary glands, oral pathology, and oral medicine. He is a member of SBPqO.

e-mall: a.lima@pucpr.br

Maria Angola Naval Machado, DDS, PhD

Dr. Machado is an Assoclate Professor in the Department of Oral Pathology, School of Dentistry at Pontificia Universidade Católica do Paraná in Curitba, Paraná, Brazil. Her research Interests Include the sallvary glands, oral pathology, and oral medicine. She is a member of LADR and SBPqO.

e-mail: m.angela@pucpr.br

Ana Marla Trindado Groglo, Pharm, PhD

Dr. Gregio is an Associate Professor and Chairman in the Department of Pharmacology at the School of Dentistry at Pontificla Universidade Catolica do Paraná, Curitiba, Paraná, Brazll. Her research Interests Include the salivary glands and pharmacology. She is a member of SBPqO.

e-mail: ana.greglo@pucprbr 